\title{
PENGARUH KUALITAS PELAYANAN TERHADAP TINGKAT KEPUASAN KONSUMEN TOUR DAN TRAVEL (Studi Kasus Pada CV. Maha Jaya Tour dan Travel di Kota Blitar )
}

\author{
Suprianto \\ Dosen Fakultas Ekonomi Universitas Balitar \\ Email: suprianto@gmail.com \\ Annisa Khusnul Fitriasih \\ Mahasiswa Fakultas Ekonomi Universitas Islam Balitar \\ Email; annisa@gmail.com
}

\begin{abstract}
Abstrak
Penelitian ini bertujuan untuk mengetahui seberapa besar pengaruh kualitas pelayanan terhadap kepuasan konsumen tour dan travel menggunakan jasa transportasi pada CV.Maha Jaya.Uji validitas instrumen menggunakan Coeficient Corelation Pearson, dan uji reliabilitas menggunakan Alpha Cronbach. Teknik analisis yang digunakan adalah analisis regresi berganda.

Hasil peneltian bahwa, secara parsial keandalan berpengaruh signifikan terhadap kepuasan konsumen dengan nilai thitung (2.785) > $t_{\text {tabel }}$ (2.014), jaminan berpengaruh signifikan terhadap kepuasan konsumen dengan nilai thitung (2.161) > tabel (2.014), daya tanggap tidak berpengaruh signifikan terhadap kepuasan konsumen dengan nilai thitung $(0.560)<t_{\text {tabel }}$ (2.014), perhatian tidak berpengaruh signifikan terhadap kepuasan konsumen dengan nilai thitung (-0.614) < tabel (2.014), dan bukti langsung tidak berpengaruh secara signifikan terhadap kepuasan konsumen dengan nilai thitung (0.991) < tabel (2.014). Dan secara simultan keandalan, daya tanggap, jaminan, perhatian, bukti langsung berpengaruh signifikan terhadap kepuasan konsumen dengan nilai Fhitung (13.952) > $t_{\text {tabel }}(2.49)$.
\end{abstract}

Kata kunci : kualitas pelayanan, kepuasan konsumen.

\section{Latar Belakang}

Industri jasa memiliki peranan penting dalam perekonomian dunia. Tjiptono (2006:15), menunjukkan di negara maju seperti Amerika Serikat, sektor jasa telah memberikan kontribusi yang semakin besar sekitar $2 / 3$ terhadap peningkatan Gross Domestic Product (GDP) dan lebih dari 50\% total pengeluaran konsumen dibelanjakan untuk jasa. Selain itu, sektor jasa juga merupakan salah satu sumber lapangan pekerjaan.

Pelayanan merupakan perilaku produsen dalam rangka memenuhi kebutuhan dan keinginan konsumen demi tercapainya kepuasan pada konsumen itu sendiri. Kualitas pelayanan service quality dapat diketahui 
dengan cara membandingkan persepsi para konsumen atas pelayanan yang nyata - nyata mereka terima / peroleh dengan pelayanan yang sesungguhnya mereka harapkan / inginkan terhadap atribut - atribut pelayanan suatu perusahaan. Jika jasa yang diterima atau dirasakan perceived service sesuai dengan yang diharapkan, maka kualitas pelayanan dipersepsikan baik dan memuaskan, jika jasa yang diterima melampaui harapan konsumen, maka kualitas pelayanan dipersepsikan sangat baik dan berkualitas. Sebaliknya jika jasa yang diterima lebih rendah daripada yang diharapkan, maka kualitas pelayanan dipersepsikan buruk.

\section{Metodologi Penelitian Jenis Penelitian}

Desain dalam penelitian ini menggunakan metode penelitian kuantitatif, yang menurut Sugiyono (2012:23) dikatakan metode kuantitatif karena data penelitian berupa angka-angka dan analisis menggunakan statistik. Metode kuantitatif digunakan apabila masalah merupakan penyimpangan antara yang seharusnya dengan yang terjadi, antara aturan dengan pelaksanaan, antara teori dengan praktik, antara rencana dengan pelaksanaan. Berdasarkan latar belakang dan rumusan masalah yang telah disebutkan,. Penelitian kuantitatif ini di tujukan untuk menganalisis kualitas pelayanan terhadap kepuasan konsumen.

\section{Metode Pengumpulan Data}

1. Interview (wawancara), proses pengumpulan data yang dilakukan dengan cara tanya jawab sambil bertatap muka secara langsung dengan pimpinan perusahaan atau instansi dan Karyawan.

2. Observasi, Yaitu pengumpulan data yang dilakukan dengan cara melakukan pengamatan langsung pada obyek penelitian serta melakukan pencatatan secara sistematis mengenai hal-hal yang diteliti.

3. Studi Pustaka yaitu dengan menggunakan buku-buku dan literatur-literatur untuk mendukung penelitian agar lebih kuat

4. Dokumentasi YaituCara pengumpulan data dengan mencatat dokumen yang ada di perusahaan sesuai dengan obyek yang diteliti.

\section{Variabel Penelitian}

1. Reliabilityyang dinyatakan dengan $\mathrm{X} 1$

Yaitu kemampuan untuk memberikan pelayanan yang dijanjikan dengan segera, akurat dan memuaskan.

\section{Responsiveness yang dinyatakan dengan X2}

Yaitu daya tanggap adalah keinginan para staf untuk membantu para pelanggan memberikan pelayanan dengan tanggap. 


\section{Assurance yang dinyatakan dengan X3}

Yaitu pengetahuan dan kesopan santunan para staf perusahaan serta kemampuan untuk menumbuhkan rasa percaya para pelanggan pada perusahaan

\section{Emphaty yang dinyatakan dengan X4}

Yaitu kemampupahaman, meliputi kemudahan dalam melakukan hubungan komunikasi yang baik, perhatian pribadi dan kemampuan memahami kebutuhan para pelanggan

\section{Tangible yang dinyatakan dengan X1}

Yaitu merupakan suatu bentuk pelayanan yang dapat dilihat secara langsung, meliputi fasilitas fisik, perlengkepan pegawai, dan sarana komunikasi

\section{Kepuasan Konsumen yang dintakan dengan $Y$}

kepuasan pelanggan merupakan evaluasi purna beli, dimana persepsi terhadap kinerja alternatif produk atau jasa yang dipilih memenuhi atau melebihi harapan sebelum pembelian. Apabila persepsi terhadap kinerja tidak bisa memenuhi harapan, maka yang terjadi adalah ketidakpuasan.

\section{Analisis Data}

\section{Uji Validitas}

Uji validitas dalam penelitian ini menggunakan perbandingan nilai $r_{\text {hitung }}$ dan nilai $r_{\text {tabel }}$ untuk mengukur valid atau tidaknya data yang telah didapatkan dengan metode kuesioner. Data dianggap valid jika memenuhi syarat validitas yaitu $r_{\text {hitung }}>r_{\text {tabel, }}$ rhitng diambil dari nilai correlation pearson.

\section{Tabel 1}

Rekapitulasi Hasil Uji Validitas Dengan SPSS

\begin{tabular}{|c|c|c|c|}
\hline Item & $(\mathbf{r}$ hitung $)$ & $\begin{array}{c}(\mathbf{r} \text { tabel }) \\
5 \%(2-\text { tailed })\end{array}$ & Kesimpulan \\
\hline $\mathbf{X 1 . 1}$ & 0.775 & 0.312 & VALID \\
\hline $\mathbf{X 1 . 2}$ & 0.878 & 0.312 & VALID \\
\hline $\mathbf{X 1 . 3}$ & 0.903 & 0.312 & VALID \\
\hline $\mathbf{X 2 . 1}$ & 0.825 & 0.312 & VALID \\
\hline $\mathbf{X 2 . 2}$ & 0.763 & 0.312 & VALID \\
\hline $\mathbf{X 2 . 3}$ & 0.701 & 0.312 & VALID \\
\hline $\mathbf{X 3 . 1}$ & 0.814 & 0.312 & VALID \\
\hline $\mathbf{X 3 . 2}$ & 0.609 & 0.312 & VALID \\
\hline
\end{tabular}




\begin{tabular}{|c|c|c|c|}
\hline $\mathbf{X 3 . 3}$ & 0.744 & 0.312 & VALID \\
\hline $\mathbf{X} 4.1$ & 0.806 & 0.312 & VALID \\
\hline $\mathbf{X} 4.2$ & 0.752 & 0.312 & VALID \\
\hline $\mathbf{X} 4.3$ & 0.698 & 0.312 & VALID \\
\hline $\mathbf{X 5 . 1}$ & 0.655 & 0.312 & VALID \\
\hline $\mathbf{X 5 . 2}$ & 0.763 & 0.312 & VALID \\
\hline $\mathbf{X 5 . 3}$ & 0.749 & 0.312 & VALID \\
\hline $\mathbf{Y . 1}$ & 0.366 & 0.312 & VALID \\
\hline $\mathbf{Y . 2}$ & 0.755 & 0.312 & VALID \\
\hline $\mathbf{Y . 3}$ & 0.648 & 0.312 & VALID \\
\hline $\mathbf{Y . 4}$ & 0.761 & 0.312 & VALID \\
\hline
\end{tabular}

sumber : data primer (2016)

Tabel tersebut menunjukkan bahwa masing - masing butir pertanyaan pada variabel tangible, variabel reliability, variabel responsiveness, variabel assurance, variabel emphaty, dan variabel kepuasan konsumen dikatakan valid. Karena hasil nilai dari correlation pearson memilki nilai yang lebih besar dari nilai $r_{\text {tabel }}$ yaitu 0.312 .

\section{Uji Reliabilitas}

Uji reliabilitas dilakukan dengan menggunakan rumus $A / p h a$ Cronbach. Pengujian dilakukan dengan cara membandingkan nilai Alpha dengan tabel tingkat keandalan. Tingkat keandalan dapat dilihat pada tabel 3.1 pada bab III.

Tabel 2

Hasil Uji Reliabilitas Dengan SPSS

\begin{tabular}{|c|l|c|c|}
\hline No. & \multicolumn{1}{|c|}{ Indikator } & $\begin{array}{c}\text { Nill Alpha } \\
\text { Cronbach }\end{array}$ & $\begin{array}{c}\text { Tingkat } \\
\text { keandalan }\end{array}$ \\
\hline 1 & Reliability & 0.813 & Sangat andal \\
\hline 2 & Responsiveness & 0.645 & Andal \\
\hline 3 & Asurance & 0.552 & Cukup andal \\
\hline 4 & Emphaty & 0.601 & Andal \\
\hline
\end{tabular}




\begin{tabular}{|c|l|c|c|}
\hline 5 & Tangible & 0.524 & Cukup andal \\
\hline 6 & Kepuasan konsumen & 0.600 & Andal \\
\hline
\end{tabular}

sumber : data primer (2016)

Tabel tersebut menunjukkan bahwa seluruh variabel penelitian dalam penelitian ini lolos uji reliabilitas dengan satu variabel penelitian memiliki tingkat keandalan dalam kategori sangat andal yaitu variabel reliability dengan nilai alpha sebesar 0.813, tiga variabel dalam kategori andal yaitu variabel responsiveness dengan nilai alpha sebesar 0.645 , variabel emphaty dengan nilai alpha sebesar 0.601, dan variabel kepuasan konsumen dengan nilai alpha sebesar 0.600 , dan dua variabel dengan kategori cukup andal yaitu variabel assurance dengan nilai a/pha sebesar 0.552 dan tangible dengan nilai alpha sebesar 0.524 .

\section{Uji Asumsi Klasik}

\section{a. Uji Normalitas}

Uji normalitas digunakan untuk melihat apakah model regresi berdistribusi normal ataukah tidak. Uji normalitas dilakukan dengan menggunakan rumus Kolmogorov - smirnov dengan bantuan SPSS yaitu dengan cara membandingkan nilai probabiltas $Z$ pada tabel Kolmogorov - smirnov dengan nilai signifikansi 5\%. Data dianggap berdistribusi normal jika nilai probabilitas Z lebih besar dari 0.05 .

Tabel 3

Rekapitulasi Hasil Uji Normalitas dengan SPSS

\begin{tabular}{|l|c|}
\hline \multicolumn{1}{|c|}{ Variabel } & Nilai Z \\
\hline Reliability & 1.277 \\
\hline Responsiveness & 1.207 \\
\hline Assurance & 1.473 \\
\hline Emphaty & 1.148 \\
\hline Tangible & 1.146 \\
\hline Kepuasan Konsumen & 1.675 \\
\hline
\end{tabular}

sumber: data primer (2016)

Tabel diatas menunjukkan bahwa variabel reliability, responsiveness, assurance, emphaty, tangible dan kepuasan konsumen berdistribusi normal karena nilai probabilitas $Z$ lebih besar dari 0.05 . 


\section{b. Uji Heteroskedastisitas}

Uji Heteroskedastisitas digunakan untuk melihat ada atau tidaknya ketidak samaan varian dalam model regresi. Untuk menguji heteroskedastisitas menggunakan uji Glejser dengan bantuan program pengolahan data statistik SPSS. Model regresi dinyatakan tidak terjadi Heteroskedastisitas jika t hitung lebih kecil dari t tabel dan jika nilai signifikansi lebih besar dari 0.05 .

\section{Tabel 4}

Rekapitulasi Hasil Uji Heteroskedastisitas Dengan SPSS

\begin{tabular}{|c|c|c|}
\hline Variabel & Nilai t Hitung & Nilai Signifikansi \\
\hline Reliability & -0.056 & 0.955 \\
\hline Responsiveness & -0.183 & 0.856 \\
\hline Assurance & -1.288 & 0.206 \\
\hline Emphaty & -0.238 & 0.813 \\
\hline Tangible & 1.241 & 0.223 \\
\hline
\end{tabular}

sumber : data primer (2016)

Tabel tersebut menunjukkan bahwa tidak terjadi Heteroskedastisitas pada model regresi dalam penelitian ini karena nilai t hitung lebih kecil dari nilai t tabel 1.686 dan nilai signifikasi lebih besar dari 0.05 .

c. Uji Multikolinieritas

Uji multikolinieritas digunakan untuk melihat ada atau tidak korelasi antar variabel bebas pada model regresi.

Tabel 5

Tabel Collinearity Statistics

\begin{tabular}{|l|c|c|}
\hline \multirow{2}{*}{ Model } & \multicolumn{2}{c|}{ Collinearity Statistics } \\
\cline { 2 - 3 } & Tolerance & VIF \\
\hline Reliability & 0.515 & 1.941 \\
\hline Responsiveness & 0.286 & 3.500 \\
\hline Assurance & 0.285 & 3.512 \\
\hline Emphaty & 0.382 & 2.618 \\
\hline Tangible & 0.434 & 2.306 \\
\hline
\end{tabular}

sumber : data primer (2016) 
Tabel tersebut menunjukkan variabel kualitas pelayanan, variabel Reliability, Responsiveness, Assurance, Emphaty, Tangible memiliki angka tolerance $>0.1$, dan nilai VIF $<10$, hal tersebut menunjukkan bahwa tidak terjadi multikolinieritas pada model regresi dalam penelitian.

\section{Analisis Regresi Berganda}

Analisis regresi berganda digunakan untuk menguji signifikan atau tidaknya hubunngan/ pengaruh variabel Reliability, Responsiveness, Assurance, Emphaty, Tangible terhadap kepuasan konsumen.

Setelah dilakukan pengujian validitas dan realibilitas pada data yang ada, serta pengujian asumsi klasik pada model regresi dalam penelitian ini dianggap layak.

\section{Tabel 6}

\section{Hasil Analisis Regresi dengan SPSS}

\section{Coefficients $^{a}$}

\begin{tabular}{|c|c|c|c|c|c|c|c|}
\hline \multirow[b]{2}{*}{ Model } & \multicolumn{2}{|c|}{$\begin{array}{l}\text { Unstandardized } \\
\text { Coefficients }\end{array}$} & \multirow{2}{*}{\begin{tabular}{|c|}
$\begin{array}{c}\text { Standardi } \\
\text { zed } \\
\text { Coefficien } \\
\text { ts }\end{array}$ \\
Beta \\
\end{tabular}} & \multirow[b]{2}{*}{$\mathrm{T}$} & \multirow[b]{2}{*}{ Sig. } & \multicolumn{2}{|c|}{$\begin{array}{l}\text { Collinearity } \\
\text { Statistics }\end{array}$} \\
\hline & B & Std. Error & & & & \begin{tabular}{|c|}
$\begin{array}{c}\text { Toleran } \\
\text { ce }\end{array}$ \\
\end{tabular} & VIF \\
\hline \begin{tabular}{|ll}
1 & (Constant)
\end{tabular} & 3.341 & 1.277 & & 2.616 & .013 & & \\
\hline Reliability & .270 & .097 & .381 & 2.785 & .009 & .515 & 1.941 \\
\hline $\begin{array}{l}\text { Responsive } \\
\text { ness }\end{array}$ & .085 & .151 & .103 & .560 & .579 & .286 & 3.500 \\
\hline Assurance & .364 & .169 & .398 & 2.161 & .038 & .285 & 3.51 \\
\hline Empathy & -.080 & .130 & -.097 & -.614 & .544 & .382 & $2.61 \varepsilon$ \\
\hline Tangible & .133 & .134 & .148 & .991 & .328 & .434 & 2.306 \\
\hline
\end{tabular}

a. Dependent Variable: Kepuasan konsumen

\section{Sumber : data primer (2016)}

Tabel tersebut menunjukkan nilai $\beta$ untuk nilai konstan sebesar - 3.341, nilai $\beta$ untuk variabel reliability sebesar 0.270 , nilai $\beta$ untuk variabel responsiveness sebesar 0.085 , nilai $\beta$ untuk variabel assurance 0.364 , nilai $\beta$ untuk variabel emphaty sebesar -0.080 , dan $\beta$ untuk variabel tangible sebesar 0.133 , dari nilai $\beta$ maka didapatkan persamaan regresi berganda :

$$
\mathrm{Y}=3.341+0.270 \mathrm{X}_{1}+0.085 \mathrm{X}_{2}+0.364 \mathrm{X}_{3}-0.080 \mathrm{X}_{4}+0.133 \mathrm{X}_{5}+\mathrm{e}
$$

Dimana $Y$ adalah variabel Kepuasan Konsumen, $X_{1}$ adalah variabel reliability, $\mathrm{X}_{2}$ adalah variabel responsiveness, $\mathrm{X}_{3}$ adalah variabel 
assurance, $\mathrm{X}_{4}$ adalah variabel emphatydan $\mathrm{X}_{5}$ adalah variabel tangible.

\section{Uji Hipotesis}

Untuk pengujian model regresi dalam penelitian ini digunakan dua cara yaitu dengan uji $\mathrm{t}$ dua arah (2-tailed) untuk menguji hubungan variabel bebas terhadap variabel tetap secara parsial, dan uji anova untuk menguji hubungan variabel bebas terhadap variabel tetap secara simultan.

1. Uji T

Pengujian model regresi dengan uji t menggunakan metode 2 arah karena masih dalam hipotesis masih belum diketahui arah hipotesis dalam penelitian ini. Untuk pengujian dengan uji $t$ dilakukan dengan membandingkan nilai t hitung dan $\mathrm{t}$ tabel dengan nilai signifikansi $5 \%$.

Tabel 7

Rekapitulasi Hasil Pengujian Parsial dengan menggunakan Uji t

\begin{tabular}{|l|l|l|l|l|l|}
\hline Variabel & $\begin{array}{l}\text { T } \\
\text { hitung }\end{array}$ & $\begin{array}{l}\text { T } \\
\text { tabel }\end{array}$ & Sig & $\mathbf{A}$ & $\begin{array}{l}\text { Keteranga } \\
\mathbf{n}\end{array}$ \\
\hline Reliability & 2.785 & 2.014 & 0.009 & 0.05 & $\begin{array}{l}\text { Berpengaru } \\
\text { h signifikan }\end{array}$ \\
\hline $\begin{array}{l}\text { Responsivene } \\
\text { ss }\end{array}$ & 0.560 & 2.014 & 0.579 & 0.05 & $\begin{array}{l}\text { Tidak } \\
\text { berpengaru } \\
\text { h signifikan }\end{array}$ \\
\hline Assurance & 2.161 & 2.014 & 0.038 & 0.05 & $\begin{array}{l}\text { Berpengaru } \\
\text { h signifikan }\end{array}$ \\
\hline Emphaty & -0.614 & 2.014 & 0.544 & 0.05 & $\begin{array}{l}\text { Tidak } \\
\text { berpengaru } \\
\text { h signifikan }\end{array}$ \\
\hline Tangible & 0.991 & 2.014 & 0.328 & 0.05 & $\begin{array}{l}\text { Tidak } \\
\text { berpengaru } \\
\text { h signifikan }\end{array}$ \\
\hline
\end{tabular}

sumber : data primer (2016)

Tabel diatas menjelaskan bahwa pada variabel reliability dan Assurance memiliki pengaruh signifikan terhadap variabel kepuasan konsumen karena telah memenuhi syarat signifikansi uji t. Sedangkan variabel Reliability,Assurance, Emphaty tidak memiliki pengaruh signifikan terhadap variabel kepuasan konsumen Karena tidak memenuhi syarat signifikansi uji t.

2. Uji ANOVA ( F ) 
Pengujian Anova atau uji $\mathrm{F}$ digunakan untuk melihat pengaruh variabel independen terhadap variabel dependen yaitu pengaruh variabel Tangible, Reliability, Responsiveness, Assurance, dan Emphaty terhadap variabel kepuasan konsumen.

\section{Tabel 8}

ANOVA

ANOVA $^{\mathrm{b}}$

\begin{tabular}{|l|r|r|r|r|r|}
\hline \multicolumn{1}{|l|}{ Model } & \multicolumn{1}{c|}{$\begin{array}{c}\text { Sum of } \\
\text { Squares }\end{array}$} & \multicolumn{1}{c|}{ Df } & \multicolumn{1}{c|}{$\begin{array}{c}\text { Mean } \\
\text { Square }\end{array}$} & \multicolumn{1}{c|}{$\mathrm{F}$} & \multicolumn{1}{c|}{ Sig. } \\
\hline $1 \quad$ Regression & 40.608 & 5 & 8.122 & 13.952 & $.000^{\mathrm{a}}$ \\
Residual & 19.792 & 34 & .582 & & \\
Total & 60.400 & 39 & & & \\
\hline
\end{tabular}

a. Predictors: (Constant), empathy, tangible, responsiveness, Assurance, reliability

b. Dependent Variable: Kepuasan konsumen

sumber : data primer (2016)

Tabel diatas menjelaskan hasil nilai $F$ hitung sebesar 13.952, nilai df1 sebesar 5 , nilai df2 sebesar 34 , nilai probabilitas signifikan sebesar 0.000. dari angka df1 dan df2 didapatkan nilai $F$ tabel sebesar 2.49. sehingga diperoleh hasil $F$ hitung lebih besar dari $F$ tabel yaitu $13.952>$ 2.49 , dan angka prob. Signifikan lebih kecil dari a yaitu $0.000<0.05$. Maka secara simultan atau bersama-sama variabel Reliability, variabel Responsiveness, variabel Assurance, variabel Emphaty, dan variabel Tangible berpengaruh signifikan terhadap variabel kepuasan konsumen.

Koefisien Determinan $\left(R^{2}\right)$

\section{Tabel 9 \\ Koefisien Regresi}

Model Summary

\begin{tabular}{|l|r|r|r|r|}
\hline Model & $\mathrm{R}$ & R Square & Adjusted R Square & $\begin{array}{c}\text { Std. Error of the } \\
\text { Estimate }\end{array}$ \\
\hline 1 & $.820^{\mathrm{a}}$ & .672 & .624 & .763 \\
\hline
\end{tabular}

a. Predictors: (Constant), Tangible, reliability, Assurance, Empathy, responsiveness

b. Dependent Variable: Kepuasan konsumen

sumber : data primer (2016)

Tabet diatas menunjukkan nilai koefisien korelasi berganda $(R)$ diperoleh sebesar 0.820, dan nilai Determinasi berganda $\left(R^{2}\right)$ sebesar 0.672 . nilai $R$ digunakan untuk mengukur keeratan hubungan variabel bebas terhadap variabel tetap. Nilai R 0.820 menunjukkan antara, 
variabel Reliability, variabel Responsiveness, variabel Assurance, variabel Emphaty, dan variabel Tangible memilki hubungan sangat kuat dengan variabel kepuasan konsumen. Sedangkan nilai determinasi $\left(R^{2}\right)$ sebesar 0.672 menunjukkan bahwa kemampuan variabel Reliability, variabel Responsiveness, variabel Assurance, variabel Emphaty, dan variabel Tangible memilki hubungan sangat kuat dengan variabel kepuasan konsumen sebesar $67,2 \%$ atau bisa dikatakan kuat.

\section{Pembahasan}

Penelitian mendapatkan hasil bahwa kepuasan konsumen dapat dijelaskan oleh faktor kualitas pelayanan dimana kualitas pelayanan dibagi menjadi lima indikator yaitu reliability atau keandalan, responsiveness atau daya tanggap, assurance atau jaminan, emphaty, dan tangible atau bukti fisik,. Diperoleh bahwa $67.2 \%$ kepuasan konsumen dapat dijelaskan oleh kelima indikator dari kualitas pelayanan tersebut.

Dari hasil pengujian variabel reliabiilty dapat disimpulkan bahwa variabel reliability memiliki pengaruh secara signifikan terhadap kepuasan konsumen terhadap jasa tour dan travel CV. Maha Jaya. Hal ini terbukti pada nilai hitung (2.785) lebih besar dari nilai t tabel (2.014) dengan nilai signifikansi 0.009 dengan menggunakan batas signifikan 0.05 . pada variabel reliability diperoleh rata-rata skor jawaban sebesar 12.55 yang berada dalam kategori sedang.

Dari hasil pengujian variabel responsiveness dapat disimpulkan bahwa variabel responsiveness tidak memiliki pengaruh secara signifikan terhadap kepuasan konsumen terhadap jasa tour dan travel CV. Maha Jaya. Hal ini terbukti pada nilai t hitung (0.560) lebih kecil dari nilai t tabel (2.014) dengan nilai signifikansi 0.579 dengan menggunakan batas signifikan 0.05. pada variabel responsiveness diperoleh rata-rata skor jawaban sebesar 12.78 yang berada dalam kategori sedang.

Dari hasil pengujian variabel assurance dapat disimpulkan bahwa variabel assurance tidak memiliki pengaruh secara signifikan terhadap kepuasan konsumen terhadap jasa tourdan trave/CV. Maha Jaya. Hal ini terbukti pada nilai t hitung (2.161) lebih kecil dari nilai t tabel (2.014) dengan nilai signifikansi 0.038 dengan menggunakan batas signifikan 0.05 . pada variabel assurance diperoleh rata-rata skor jawaban sebesar 12.95 yang berada dalam kategori sedang.

Dari hasil pengujian variabel emphaty dapat disimpulkan bahwa variabel emphaty tidak memiliki pengaruh secara signifikan terhadap kepuasan konsumen terhadap jasa tour dan travel CV. Maha Jaya. Hal ini terbukti pada nilai t hitung $(-0.614)$ lebih kecil dari nilai t tabel (2.014) dengan nilai signifikansi 0.544 dengan menggunakan batas signifikan 0.05 . pada variabel emphaty diperoleh rata-rata skor jawaban sebesar 13.20 yang berada dalam kategori sedang.

Dari hasil pengujian variabel tangible dapat disimpulkan bahwa variabel tangible tidak memiliki pengaruh secara signifikan terhadap 
kepuasan konsumen terhadap jasa tour dan trave/CV. Maha Jaya. Hal ini terbukti pada nilai t hitung (0.991) lebih kecil dari nilai t tabel (2.014) dengan nilai signifikansi 0.328 dengan menggunakan batas signifikan 0.05 . pada variabel tangible diperoleh rata-rata skor jawaban sebesar 12.92 yang berada dalam kategori sedang.

Dari hasil uji t yang dilakukan pada 5 variabel independen ternyata hanya dua variabel independen yang memiliki pengaruh signifikan terhadap variabel dependen yaitu variabel kepuasan konsumen. Diantaranya variabel reliability dan assurance, sedangkan untuk variabel responsiveness, variabel Emphaty, dan variabel tangible tidak berpengaruh signifikan terhadap kepuasan konsumen. Namun kelima variabel independen tersebut akan berpengaruh signifikan jika secara simultan atau bersama-sama mempengaruhi kepuasan konsumen terhadap penggunaan jasa tour dan trave/CV. Maha Jaya. Hal ini terbukti pada nilai t hitung (0.991) lebih kecil dari nilai $F$ tabel (13.952) dengan nilai signifikansi 0.000 dengan menggunakan batas signifikan 0.05 .

\section{Kesimpulan}

Mengacu pada rumusan masalah, tujuan penelitian, dan hasil penelitian serta pembahasan yang telah dipaparkan maka dapat diambil kesimpulan hasil penelitian pengaruh kualitas pelayanan terhadap tingkat kepuasan konsumen tour dan travel adalah " Secara parsial tingkat reliability dan assurance pada kualitas pelayanan memiliki pengaruh signifikan terhadap penggunaan jasa tour dan travel CV. Maha Jaya, sedangkang tingkat responsiveness, emphaty, dan tangible pada kualitas pelayanan tidak berpengaruh signifikan terhadap penggunaan jasa tour dan travel CV. Maha Jaya, sedangkan secara simultan reliability, responsiveness, assurance, emphaty, dan tangible berpengaruh signifikan terhadap penggunaan jasa tourdan trave/CV. Maha Jaya".

\section{Saran}

Banyak pesaing dalam usaha yang sama, sebaiknya pelayanan yang telah dimiliki harus lebih ditingkatkan lagi, agar lebih baik sehingga dengan memiliki pelayanan yang baik akan mampu mempengaruhi konsumen untuk menjadi pelanggan jasa transportasi CV.Maha Jaya tour dan travel.

Bagi perusahaan tour dan travel diharapkan lebih meningkatkan kinerjanya dalam melayani konsumen, perusahaan tour dan travel harus meningkatkan kualitas pelayanan terutama professional dan proposional dalam bekerja, karena ini merupakan modal, dasar dalam menjalankan aktifitas. Sikap sopan dan santun kepada konsumen saat mengadakan transaksi melayani konsumen yang komplain terhadap pelayanan perusahaan bukan menghakimi adalah sikap yang harus dijaga untuk kedepannya. Kebersamaan dan kekompakan serta rasa memiliki terhadap perusahaan perlu dijaga dan dimantapkan untuk menunaikan visi dan misi 
perusahaan dalam mencapai tujuan, sehingga konsumen mendapatkan pelayanan yang memuaskan dan citra positif perusahaan tetap terjaga.

Bagi peneliti selanjutnya dapat mencari ruang lingkup konsumen

yang berbeda dan lebih luas serta menggunakan sampel yang lebih banyak lagi dengan variabel yang berbeda dengan perusahaan yang sama.

\section{Daftar Pustaka}

Abdul, Kadir. 2001, Dasar Pemrograman Web Dinamis .

Yogyakarta : PHP, C.V Andi Offset.

Adiwiyoto, Anton, 1997, Mendahulukan Pelanggan, Jakarta: Binarupa Aksara.

Arikunto, Suharsimi. 1998. Prosedur Penelitian Suatu Pendekatan Praktek. Jakarta : Rineka Cipta.

Assegaff, Mohammad. 2009. Pengaruh Kualitas Pelayaanan Terhadap Kepuasa Pelanggan, (Studi Pada Perusahaan Penerbangan PT. Garuda Di Kota Semarang) Jurnal Ekonomi dan Bisnis. Vol. 10. No. 2. Juli. Semarang: Unisulla Semarang.

Azwar, Saifudin. 1997. Reliabilitas dan Validitas. Edisi 3. Yogyakarta: Pustaka Pelajar.

Bitner, Mary Jo. 2000. Evaluating Service Encounters: The effect of Physical Surrounding and Employee Responses. Journal of Marketing.

Garvin \& Davis. 2005. Manajemen Mutu Terpadu. Terjemahan M.N. Nasution. Erlangga

Ghozali, Imam. 2005. Analisis Multivariate Dengan Program SPSS.

Semarang : Badan Penerbit Universitas Diponegoro.

H.A.S Moenir. 1995. Manajemen Pelayanan Umum. Jakarta : PT. Bumi Aksara.

Hair, Joseph F et al. 2010. Multivariate Data Analysis Edisi Tujuh. Jakarta : Gramedia Puastaka Utama.

Hasan, Iqbal. 2004. Analisis Data Penelitian Dengan Statistik, Cetakan Pertama. Jakarta : PT. Bumi Aksara.

Koentjaraningrat. 1994. Pengantar Antropologi I. Jakarta : Renika Cipta. .1997. Metode Penelitian masyarakat. Jakarta : PT. Gramedia Pustaka Utama.

Kotler, Philip dan gary Armstrong, 2003, Dasar-dasar Pemasaran, Jilid 1, Edisi Kesembilan, Jakarta: PT. Indeks Gramedia.

Kotler, Philip, 2000. Manajemen Pemasaran, Edisi Milenium, Jakarta, Prehallindo.

Kotler, Philip. 2002, Manajemen Pemasaran, Jilid 1, Edisi Milenium. Jakarta : Prehallindo. 